\title{
Resolution of Late Steroid-Responsive Nephrotic Syndrome in a Patient with Alport Syndrome Treated with Atorvastatin
}

\author{
Jia-Feng Chang ${ }^{1,2}$, Wei-Ning Lin ${ }^{1}$, Chien-Chen Tsai ${ }^{*}$ \\ ${ }^{1}$ Graduate Institute of Basic Medicine, Fu Jen Catholic University, Taipei, Taiwan \\ ${ }^{2}$ Division of Nephrology, Department of Internal Medicine, Far Eastern Memorial Hospital, New Taipei City, \\ Taiwan \\ ${ }^{3}$ Department of Anatomic Pathology, Far Eastern Memorial Hospital, New Taipei City, Taiwan \\ Email: ${ }^{*}$ cjf6699@yahoo.com.tw
}

Received 3 January 2015; accepted 29 January 2015; published 2 February 2015

Academic Editor: Ashraf Mohamed Abdel-Basset Bakr, Mansoura University Children's Hospital, Egypt

Copyright (C) 2015 by authors and Scientific Research Publishing Inc.

This work is licensed under the Creative Commons Attribution International License (CC BY).

http://creativecommons.org/licenses/by/4.0/

(c) (i) Open Access

\begin{abstract}
Experimental and clinical studies have pointed out the lipid-induced renal damage, and statins may have pleiotropic effects on renoprotection. We reported a girl with X-linked Alport syndrome whose late steroid-responsive nephrotic syndrome (NS) was resolved by atorvastatin. She had been in a nephrotic condition despite of prednisone therapy $60 \mathrm{mg} /$ day for 8 weeks. Renal biopsy dispicted extreme foamy appearance of tubular epithelial cells with detachment led to luminal obliteration. Atorvastatin was started on the ninth week of prednisone therapy due to severe hypercholesterolemia. Partial remission of NS was dramatically achieved with unchanged dosage of prednisone at the end of the twelfth week. Our case provides a pathology-based evidence to support the use of statins in profoundly hyperlipidemic patients with NS. In patients with NS and profound hyperlipidemia, early initiation of statin therapy is required in combination with immunosuppressive therapy.
\end{abstract}

\section{Keywords}

Nephrotic Syndrome, Statin

\section{Introduction}

Experimental and clinical studies have pointed out the lipid-induced renal damage [1], and statins may have ${ }^{*}$ Corresponding author.

How to cite this paper: Chang, J.-F., Lin, W.-N. and Tsai, C.-C. (2015) Resolution of Late Steroid-Responsive Nephrotic Syndrome in a Patient with Alport Syndrome Treated with Atorvastatin. Open Journal of Pediatrics, 5, 12-16. 
pleiotropic effects on renoprotection [2]. Lowering serum concentrations of cholesterol and triglycerides by lipid-apheresis or statin therapy improves the response to steroids in pediatric nephrotic syndrome (NS) [3]-[6]. We reported the case of a girl with X-linked Alport syndrome whose late steroid-responsive nephrotic syndrome (NS) was resolved by atorvastatin. To our best knowledge, there was no study showing pathology-based evidence to support the use of statins in profoundly hyperlipidemic patients with NS.

\section{Case Report}

A 12-year-old girl presented with puffy face, bilateral lower-leg edema and frothy urine in recent two months. Biochemical studies showed nephrotic range proteinuria, hematuria $>30$ erythrocytes per high-power field, lipiduria, serum cholesterol $10.1 \mathrm{mmol} / \mathrm{l}$, albumin $16 \mathrm{~g} / \mathrm{l}$, and creatinine $30.5 \mathrm{mmol} / \mathrm{l}$. Her blood pressure was 108/70 mmHg, and renin-angiotensin system blockers were not used. A kidney biopsy was performed for her nephrotic-nephritic syndrome with unclear etiology. Light microscopic examination with hematoxylin and eosin stain revealed rigidity and moderate thickening of the glomerular basement membrane (GBM), and segmental glomerular sclerosis. Accumulating an excessive amount of neutral fats in renal tubular cells led to extremely foamy appearance and luminal obliteration (Figure 1). Such fatty change is followed by necrosis of injured cells and detachement from the basement membranes compounding luminal obliteration. Electron microscopy depicted irregular distribution of GBM with basket-weave appearance (thinning, thickening, splitting and lamination of lamina densa) and diffuse effacement of podocyte foot processes (Figure 2). Myriad intracellular lipid droplets were noted within tubulointerstitial lipid-laden foamy macrophages (Figure 3).

The pathological finding pointed out the burden of lipid-induced renal damage. Compatible with her renal pathology, she had been in a nephrotic condition despite of prednisone therapy $60 \mathrm{mg} /$ day for 8 weeks. Atorvastatin was started at a dose of $10 \mathrm{mg} /$ day on the ninth week of prednisone therapy due to her progressive hypercholesterolemia $(16.0 \mathrm{mmol} / \mathrm{l})$. Partial remission of NS (proteinuria $<3 \mathrm{~g} / 24 \mathrm{~h}$ ) was dramatically achieved at the end of the twelfth week. The dosage of prednisone (60 mg/day) had not been changed since the inclusion of atorvastatin. Therefore, atorvastatin may resolve proteinuria by improving hyperlipidemia and lipid-induced renal damage.

\section{Discussion}

Studies have reported statins have pleiotropic effects on improving glomerular damage, preventing glomerulosclerosis and tubulointerstitial fibrosis [2]. Lowering serum concentrations of cholesterol and triglycerides by lipid-apheresis or statin therapy improves the response to steroids in pediatric NS [3]-[6]. In obese animal models,

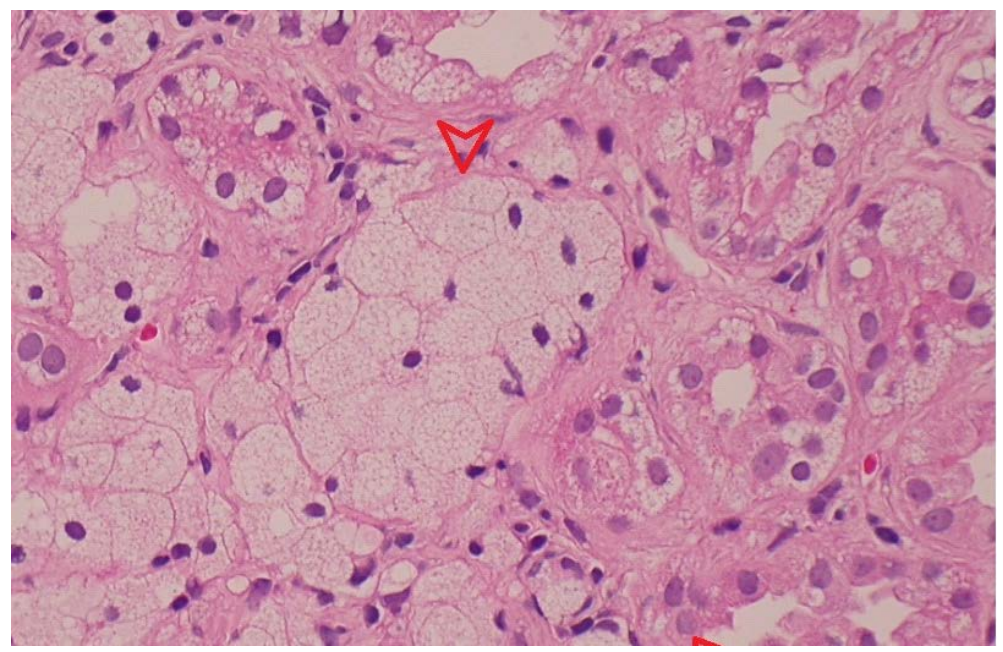

Figure 1. Light microscopy depicted accumulating excessive lipids in renal tubular cells led to extremely foamy appearance and luminal obliteration (arrow). Such fatty change is followed by necrosis of injured cells and detachement from the basement membranes (arrow) compounding luminal obliteration. 


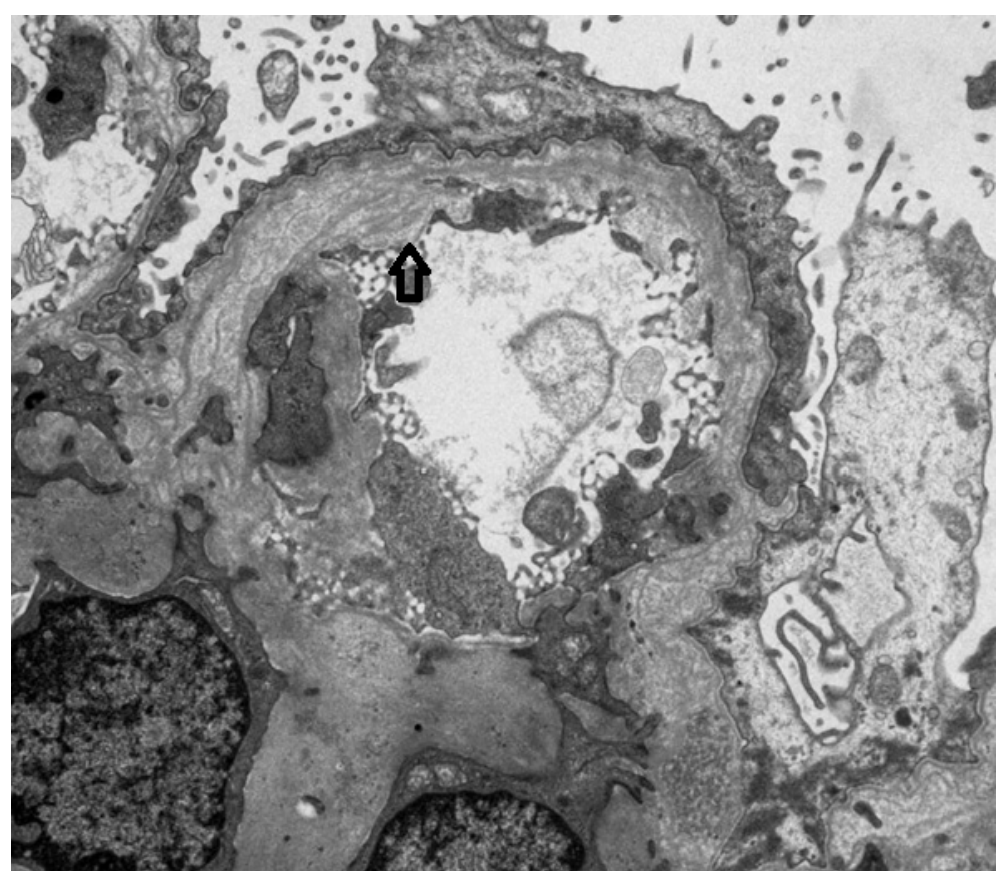

Figure 2. Electron microscopy demonstrated irregular distribution of glomerular basement membrane with basket-weave appearance (thinning, thickening, splitting and lamination of lamina densa; arrow), and effacement of podocyte foot processes.

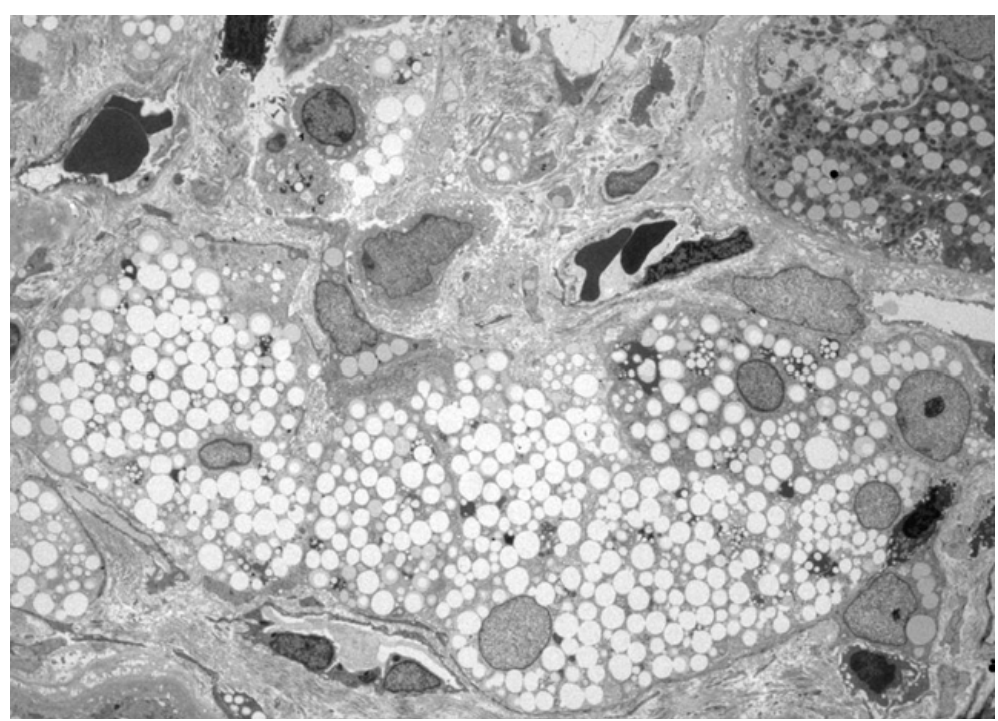

Figure 3. Myriad intracellular lipid droplets were noted within tubulointerstitial lipid-laden foamy macrophages.

lipid accumulation in kidneys accentuated glomerulosclerosis and proteinuria [7]. Compared with non-treated obese animals, statins attenuated lipid accumulation in the proximal tubules and reduced glomerular hypertrophy [8]. In experimental anti-glomerular basement membrane glomerulonephritis, the anti-proteinuric effect of atorvastatin is mediated through anti-inflammatory responses [9] [10].

To our best knowledge, this is the first case of a hyperlipidemic patient whose late steroid-responsive NS was resolved by atorvastatin with a pathology-based evidence of lipid-induced kidney injury. The renal pathology revealed extremely foamy tubular cells and detachment of injured cells from the basement membranes. Such results led to obliterate renal tubular lumens, increased intratubular pressure, tubulointerstitial edema and de- 
creased glomerular filtration rate. Thus we initiated atorvastatin in this patient to treat her progressive hypercholesterolemia and lipid-induced kidney injury. Her nephritic range proteinuria and severe hypercholesterolemia were significantly ameliorated with atorvastatin, accompanied with elevated serum albumin level and edema resolution. The baseline therapeutic doses of prednisone and diuretic regimen were not changed. The reasons why the combination therapy of prednisone and atorvastatin became more effective for NS included but not limited to the following. On one hand, statins have direct anti-proteinuric effects on both podocytes and renal tubular epithelial cells by preventing oxidized low-density lipoprotein-induced damage [11] [12]. On the other hand, pleiotropic effects of statins include modification of endothelial function, immunomodulation and anti-inflammation [13]. Based on the pathological evidence, atorvastatin may have an effect on ameliorating the extremely foamy change of renal tubular cells with subsequent apoptosis, and thereby relieving renal tubular obstruction. The appropriateness of statins in pediatric patients is the major concern [14]. Adverse effects of statins, such as muscle injury and liver toxicity, were not found in our patient. Study reported short-term use of statins is safe and efficient in the hyperlipidemic pediatric patients, but long-term safety is unknown [15]. Implementing statin therapy in children with nephrotic syndrome should be carefully followed up [16].

\section{Conclusion}

Our case provided a pathology-based evidence to support the use of statins in profoundly hyperlipidemic patients with NS. It suggests statins have anti-proteinuric effects by lowering lipid-induced renal damage and improve the response to steroid treatment. In profoundly hyperlipidemic patients with NS, early initiation of statin therapy is required in combination with immunosuppressive therapy.

\section{References}

[1] Kiss, E., Kränzlin, B., Wagenblaß, K., Bonrouhi, M., Thiery, J., Gröne E., Nordström, V., Teupser, D., Gretz, N., Malle, E. and Gröne, H.J. (2013) Lipid Droplet Accumulation Is Associated with an Increase in Hyperglycemia-Induced Renal Damage: Prevention by Liver X Receptors. The American Journal of Pathology, 182, 727-741. http://dx.doi.org/10.1016/j.ajpath.2012.11.033

[2] Trevisan, R., Dodesini, A.R. and Lepore, G. (2003) Lipids and Renal Disease. Journal of the American Society of Nephrology, 17, S145-S147. http://dx.doi.org/10.1681/ASN.2005121320

[3] Hattori, M., Chikamoto, H., Akioka, Y., Nakakura, H., Ogino, D., Matsunaga, A., Fukazawa, A., Miyakawa, S., Khono, M., Kawaguchi, H. and Ito, K. (2003) A Combined Low-Density Lipoprotein Apheresis and Prednisone Therapy for Steroid-Resistant Primary Focal Segmental Glomerulosclerosis in Children. American Journal of Kidney Diseases, 42, 1121-1130. http://dx.doi.org/10.1053/j.ajkd.2003.08.012

[4] Ito, S., Machida, H., Inaba, A., Harada, T., Okuyama, K., Nakamura, T., Aihara, Y. and Yokota, S. (2007) Amelioration of Steroids and Cyclosporine-Resistant Nephrotic Syndrome by Pravastatin. Pediatric Nephrology, 22, 603-606. http://dx.doi.org/10.1007/s00467-006-0371-4

[5] Prescott Jr., W.A., Streetman, D.A. and Streetman, D.S. (2004) The Potential Role of HMG-CoA Reductase Inhibitors in Pediatric Nephrotic Syndrome. Annals of Pharmacotherapy, 38, 2105-2114. http://dx.doi.org/10.1345/aph.1D587

[6] Sanjad, S.A., Al-Abbad, A. and Al-Shorafa S. (1997) Management of Hyperlipidemia in Children with Refractory Nephrotic Syndrome: The Effect of Statin Therapy. The Journal of Pediatrics, 130, 470-474. http://dx.doi.org/10.1016/S0022-3476(97)70213-0

[7] Jiang, T., Wang, Z., Proctor, G., Moskowitz, S., Liebman, S.E., Rogers, T., Lucia, M.S., Li J. and Levi, M. (2005) Diet-Induced Obesity in C57BL/6J Mice Causes Increased Renal Lipid Accumulation and Glomerulosclerosis via a Sterol Regulatory Element-Binding Protein-1c-Dependent Pathway. The Journal of Biological Chemistry, 280, 3231732325. http://dx.doi.org/10.1074/jbc.M500801200

[8] Gotoh, K., Masaki, T., Chiba, S., Ando, H., Fujiwara, K., Shimasaki, T., Tawara, Y., Toyooka, I., Shiraishi, K., Mitsutomi, K., Anai, M., Itateyama, E., Hiraoka, J., Aoki, K., Fukunaga, N., Nawata, T. and Kakuma, T. (2013) Effects of Hydrophilic Statins on Renal Tubular Lipid Accumulation in Diet-Induced Obese Mice. Obesity Research \& Clinical Practice, 7, e342-e352. http://dx.doi.org/10.1016/j.orcp.2013.04.001

[9] Eller, P., Eller, K., Wolf, A.M., Reinstadler, S.J., Tagwerker, A., Patsch, J.R., Mayer, G. and Rosenkranz, A.R. (2010) Atorvastatin Attenuates Murine Anti-Glomerular Basement Membrane Glomerulonephritis. Kidney International, 77, 428-435. http://dx.doi.org/10.1038/ki.2009.478

[10] Fujita, E., Shimizu, A., Masuda, Y., Kuwahara, N., Arai, T., Nagasaka, S., Aki, K., Mii, A., Natori, Y., Iino, Y., Katayama, Y. and Fukuda, Y. (2010) Statin Attenuates Experimental Anti-Glomerular Basement Membrane Glomerulonephritis Together with the Augmentation of Alternatively Activated Macrophages. The American Journal of Patholo- 
gy, 177, 1143-1154. http://dx.doi.org/10.2353/ajpath.2010.090608

[11] Bussolati, B., Deregibus, M.C., Fonsato, V., Doublier, S., Spatola, T., Procida, S., Di Carlo, F. and Camussi, G. (2005) Statins Prevent Oxidized LDL-Induced Injury of Glomerular Podocytes by Activating the Phosphatidylinositol 3Kinase/AKT-Signaling Pathway. Journal of the American Society of Nephrology, 16, 1936-1947. http://dx.doi.org/10.1681/ASN.2004080629

[12] Chu, G., Jia, R. and Yang, D. (2006) Fluvastatin Prevents Oxidized Low-Density Lipoprotein-Induced Injury of Renal Tubular Epithelial Cells by Inhibiting the Phosphatidylinositol 3-Kinase/Akt-Signaling Pathway. Journal of Nephrology, 19, 286-295.

[13] Steffens, S. and Mach, F. (2006) Drug Insight: Immunomodulatory Effects of Statins-Potential Benefits for Renal Patients? Nature Clinical Practice Nephrology, 2, 378-387. http://dx.doi.org/10.1038/ncpneph0217

[14] Stein, E.A. (2007) Statins and Children: Whom Do We Treat and When? Circulation, 116, 594-595. http://dx.doi.org/10.1161/CIRCULATIONAHA.107.717777

[15] Vuorio, A., Kuoppala, J., Kovanen, P.T., Humphries, S.E., Strandberg, T., Tonstad, S. and Gylling, H. (2010) Statins for Children with Familial Hypercholesterolemia. Cochrane Database of Systematic Reviews, 7, CD006401.

[16] Prescott Jr., W.A., Streetman, D.A. and Streetman, D.S. (2004) The Potential Role of HMG-CoA Reductase Inhibitors in Pediatric Nephrotic Syndrome. Annals of Pharmacotherapy, 38, 2105-2114. http://dx.doi.org/10.1345/aph.1D587 
Scientific Research Publishing (SCIRP) is one of the largest Open Access journal publishers. It is currently publishing more than 200 open access, online, peer-reviewed journals covering a wide range of academic disciplines. SCIRP serves the worldwide academic communities and contributes to the progress and application of science with its publication.

Other selected journals from SCIRP are listed as below. Submit your manuscript to us via either submit@scirp.org or Online Submission Portal.
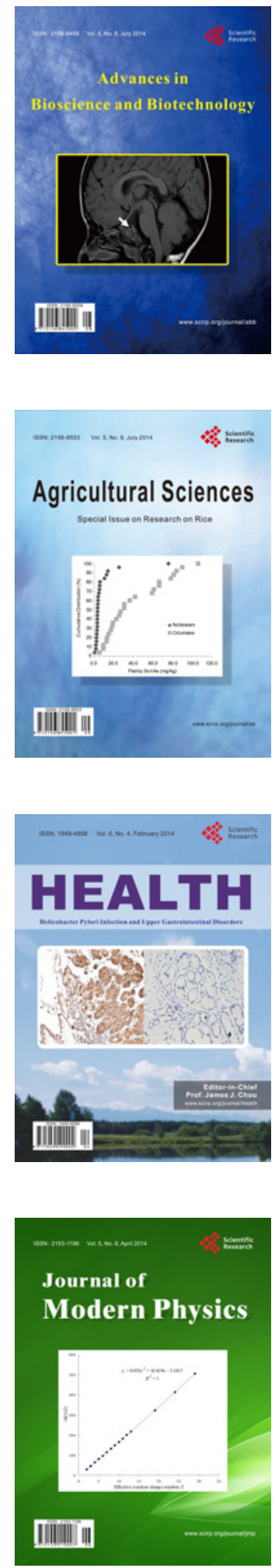
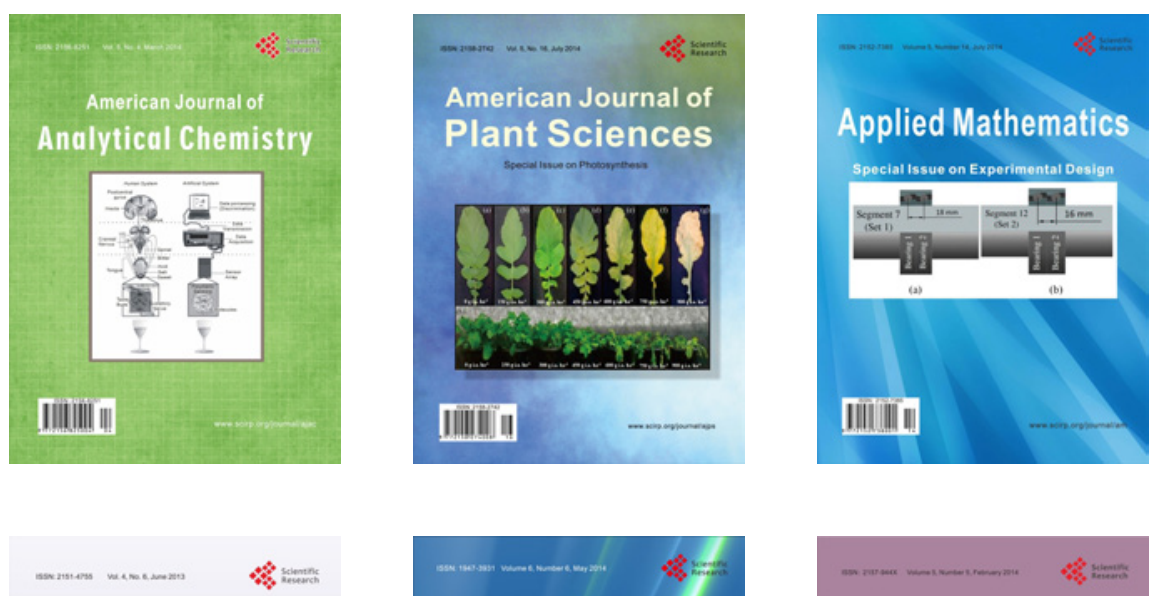

Creative Education
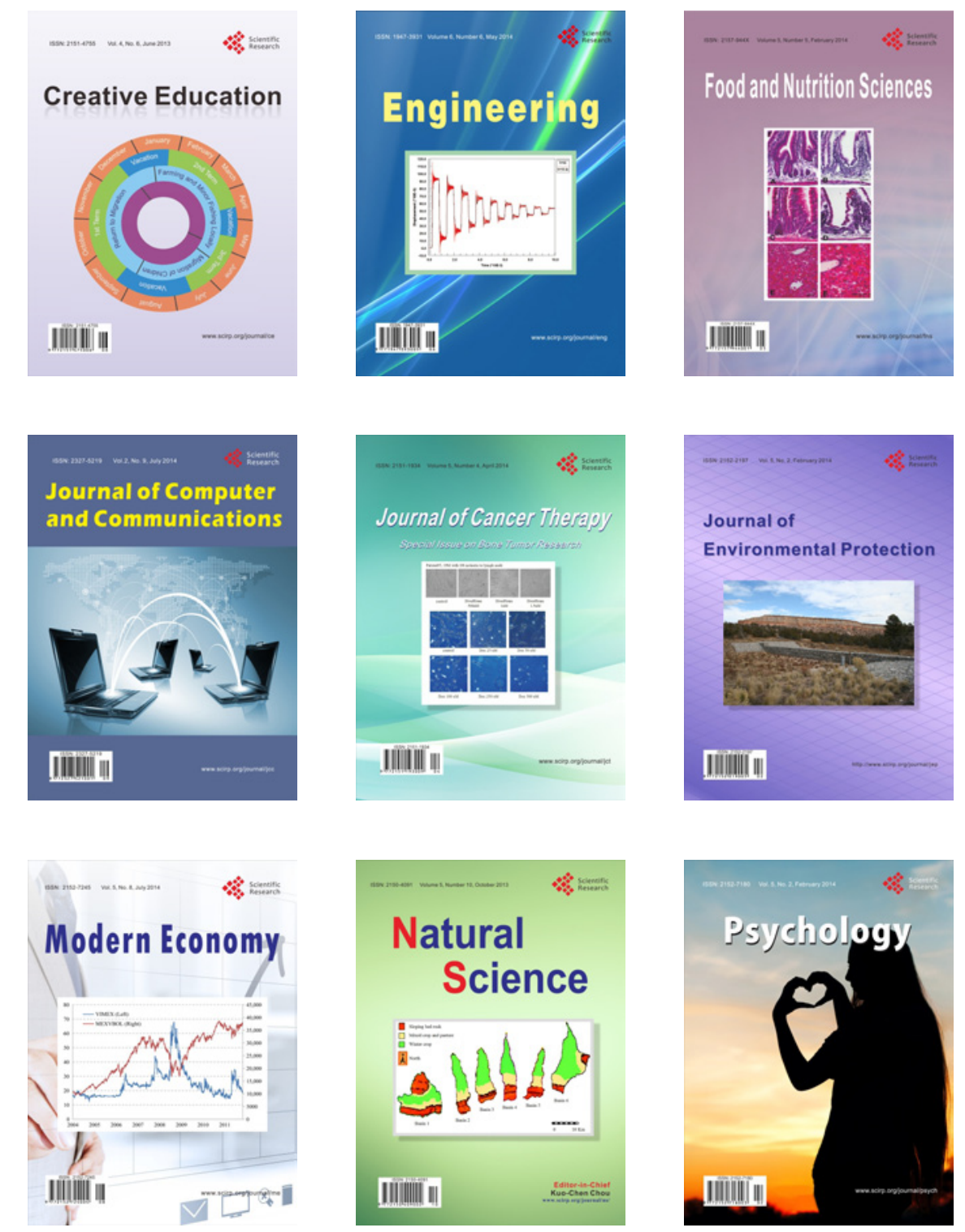